\title{
¿ES INEVITABLE UN MÍNIMO DE DOGMATISMO?
}

Armando Cíntora*

\section{Resumen}

Se argumenta que la actitud racional, así como los métodos y metas básicas de la ciencia son - sin circularidad - injustificables, y que han de ser meramente aceptados, que tienen el carácter lógico de dogmas o axiomas. Esta situación establece límites lógicos a la racionalidad y crea la posibilidad lógica de un relativismo de fundamentos.

Llamar a alguien dogmático es hoy en día un insulto ¿pero es justa esta acusación? en otras palabras ¿es posible eludir todo dogmatismo?

Voy argumentar que un mínimo núcleo de dogmas metodológicos es inevitable, que no podemos eludir un mínimo dogmatismo. Y si alguien ha de ser justamente criticado como dogmático será sólo porque su dogmatismo rebasa este mínimo núcleo dogmático.

I. En el Eutifrón, Platón sugiere que la actitud racional ${ }^{1}$ sea caracterizada como la búsqueda de justificaciones para nuestras creencias y acciones. Esta recomendación será recogida posteriormente tanto por los cartesianos como por los humeanos. Para ambos, demostrar la ca-

* Departamento de Filosofía, UAM-I, Conacyt.

${ }^{1} \mathrm{Si}$ la racionalidad es una actitud, entonces es básicamente un atributo de las personas y será sólo derivativamente una atributo de las creencias, los fines y las acciones. 
rencia de justificación, por ejemplo, de una creencia es equivalente a mostrar que la creencia no puede ser aceptada racionalmente. ${ }^{2}$ Estas dos tradiciones si bien coinciden en identificar racionalidad con justificación, difieren en el carácter de las autoridades invocadas en sus justificaciones: los cartesianos invocan la autoridad de intuiciones intelectuales, los humeanos la autoridad de las experiencias sensoriales. La actitud racional, según estas tradiciones, es la de $P$.

$P$ : "No aceptaré ninguna posición, acción, o meta, que no pueda ser justificada por la experiencia o el argumento.' 3

Ahora, la actitud descrita por $P$ puede sólo ser aceptada por aquellos que valoren el argumento y la experiencia, pues no es posible con argumentos, o evidencias empíricas, convencer, a quien no los valora, a valorarlos. No es posible convencer con argumentos a alguien a adoptar la actitud racional, si ese alguien no cree en el valor de la argumentación. Es decir, $P$ será sólo aceptada por aquellos que, al menos inconscientemente, ya hayan aceptado $P$ y por ende el valor del argumento o la experiencia.

72 La adopción de la actitud racional misma, no puede ser justificada racionalmente sin circularidad, pues requiere de su propia aceptación si alguien la ha de adoptar racionalmente. La actitud $P$ es por ende autorreferencialmente inconsistente y por lo tanto falsa.

Pero aún si por imposible $P$ no fuese inconsistente, todavía tendríamos que lidiar con la regresión al infinito, la que nos conduciría a una incesante demanda de justificación, como la recomendada por $P$. Re-

${ }^{2}$ Cfr., M. A. Notturno, "The Evolutionary Turn: A Role for Philosophy?" en Evolution, Cognition and Realism, 1990, USA, University Press of America, p. 94; W. W. Bartley, The Retreat to Commitment, 1984, Illinois, Open Court, p. 115.

${ }^{3}$ Los argumentos en cuestión pueden ser del tipo medios-fines; por ejemplo, en el caso de las acciones o métodos éstos serían justificados si hay buenas razones para considerarlos como los más eficaces para el logro de metas argumentadas como valiosas o deseables. 
¿DOGMATISMO INEVITABLE?

gresión que sólo podría ser detenida con una afirmación dogmática, o lo que es lógicamente equivalente, con una 'justificación' circular, es decir, con una mera reiteración - como ya lo hiciera notar Sextus Empiricus.

II. Debido a la injustificabilidad de $P$, Popper concluyó que la actitud racional ha de ser adoptada como resultado de una decisión irracional, o a-racional, es decir, como resultado de un acto de fe. ${ }^{4}$ De esta forma la irracionalidad, o la a-racionalidad, tiene prioridad lógica sobre la actitud racional. El compromiso con la razón, el compromiso más básico del racionalista, tiene que aceptarse gratuitamente, sin fundamento, dogmáticamente. Porque si se nos pidiese una justificación de nuestra actitud racional, lo más que podríamos hacer es reafirmar, reiterar, nuestra preferencia por la razón. En esta concepción popperiana la razón está lógicamente limitada y la actitud racional, no es —no puede ser- racional.

Como resultado de esta situación, la razón proporciona una excusa a todo tipo de dogmáticos para que se aferren a sus axiomas. Ya que si el dogmático es criticado por el racionalista, éste siempre puede responder con un tu quoque. En otras palabras, puede decir:

¡Pero si tú también eres un dogmático! ¡Pero, si tú también eres un irracionalista!

Si tu compromiso con la razón es sólo un dogma ¿entonces cómo puedes racionalmente criticar a otros dogmáticos?

Y así se crea la posibilidad de una Babel de diversos dogmas, de diferentes ecclesias, todos igualmente legítimos, aunque sólo de acuerdo a sus propias luces. Se abren así las compuertas a un relativismo de diferentes fundamentos.

${ }^{4}$ Cfr., R. Karl Popper, The Open Society and its Enemies, 1945, London, Routledge, p. 230-1. 
ARMANDO CÍNTORA

III. W. W. Bartley, enfatizó este punto, y creyó poder evadir esta falta de auto-inclusión de la actitud racional si sustituía la búsqueda de justificaciones por la búsqueda de criticabilidad. Con esta modificación podríamos caracterizar la actitud racional como $Q$.

$Q:$ es la actitud de quien considera toda posición como abierta a la crítica, la de quien no tiene compromisos, ni siquiera con su actitud racional. Por lo tanto este racionalista pan-critico no requiere de ningún acto de fe irracional, o a-racional, y justifica nada y considera todo como criticable, inclusive su misma actitud racional.

La disposición del héroe bartleyeano a criticar todo, implica que para Bartley aún las verdades necesarias son criticables, aunque la critica de tales verdades, puede estar condenada al fracaso.

Criticable no es lo mismo que revisable, ni lo mismo que posiblemente falso. Criticable, es más bien, una ausencia de compromiso, de adicción intelectual, por cualquier posición.

Una de las dificultades con esta teoría de la racionalidad es la vaguedad del término 'criticable', pero una dificultad aún más seria es que conduce a una paradoja análoga a la del mentiroso: si se supone que Q es falsa, entonces se concluye que $Q$ es verdadera; también si se supone que $Q$ es verdadera, entonces se concluye que es falsa. Por ejemplo, considérese el siguiente argumento simplificado ${ }^{5}$ que proporciona una posible interpretación de la teoría de Bartley:

${ }^{5}$ Como F. J. Post ha puntualizado, este argumento es defectuoso porque presupone implícitamente que si una posición es falsa, entonces existe un argumento que la muestra como falsa. Esto es lógicamente equivalente a decir que si no hay un argumento que muestre una posición como falsa, entonces no es falsa y es verdadera. Y este último presupuesto es inconsistente con una concepción realista de la verdad, como la de Bartley. Post mejoró el argumento, pero la paradoja persistió. Cfr., F. J. Post, "A Goedelian Theorem for Theories of Rationality", (1987), en G. Radnitzky and W. W. Bartley 
¿DOGMATISMO INEVITABLE?
(A) Todas las posiciones son criticables
(B) A es criticable

Como (B) se infiere de (A), cualquier critica de (B) será una critica de (A), y muestra que (A) es criticable. Suponiendo que una critica de (B) consista en argüir que (B) es falsa, podemos argüir: si (B) es falsa, entonces (A) es falsa; pero un argumento que muestre (A) como falsa ( $\mathrm{y}$ que por ende la critique) muestra que (B) es verdadera. Así, si (B) es falsa, entonces (B) es verdadera. Cualquier intento por criticar (B) demuestra (B); de modo que (B) no es criticable, y (A) es falsa. ${ }^{6}$

Esta paradoja es resultado de la pretensión de esta teoría de ser una teoría de toda teoría, inclusive de sí misma. El racionalismo pan-crítico es por lo tanto auto-referencialmente inconsistente. $Y$ el esfuerzo de Bartley por proporcionar una teoría de la racionalidad consistente y completamente incluyente (es decir sin compromisos irracionales o aracionales) ha fracasado.

De modo que hemos de resignarnos a la racionalidad limitada y autoexcluyente del Popper de la primera edición de The Open Society, como la única opción viable. Una racionalidad limitada por una decisión no racional por la racionalidad misma. Una decisión que como hemos visto no es justificable sin circularidad, ni criticable sin paradoja.

IV. Otra concepción de la racionalidad sumamente influyente es la que encontramos en la Ética nicomaquea, en Hume, los utilitaristas y Quine, entre otros muchos.

Según esta concepción es racional quien selecciona los medios óptimos para alcanzar sus fines, y justifica esta selección. En esta concepción medios/fines o instrumental de la racionalidad, las creencias o

(eds.), Evolutionary Epistemology, Rationality, and the Sociology of Knowledge, 1988, Illinois, Open Court, III, p. 265.

${ }^{6}$ Bartley, op. cit., p. 224. 


\section{ARMANDO CÍNTORA}

teorías son racionales si son validadas por los métodos óptimos para el logro de algunas metas cognitivas consideradas como valiosas, tales como la predicción o la verosimilitud.

Esta concepción acepta que la búsqueda de justificación es una característica de la racionalidad, pero agrega que las acciones, los métodos han de ser instrumentalmente eficaces si han de ser racionales.

Esta caracterización de la racionalidad ha sido criticada como incompleta, pues si los fines buscados no son racionales por más justificada que sea la supuesta eficacia de los medios seleccionados para alcanzarlos, no puede ser plenamente racional. El desear nuestras metas puede ser suficiente para explicarlas como nuestras, pero no es suficiente para calificarlas como racionales, para esto último tendríamos que indagar no lo que preferimos, sino más bien, lo que debemos preferir, lo que es preferible.

Por otro lado, la racionalidad medios/fines tampoco puede ser justificada racionalmente sin circularidad. Si se nos pregunta ¿por qué he de ser instrumentalmente racional? Constestamos: porque es racional optimizar el logro de tus metas. Pero esta respuesta es una mera reafirmación de la doctrina que queremos justificar. Así pues, la racionalidad instrumental o de medios/fines ha de ser aceptada también dogmáticamente. ${ }^{7}$ Se podría intentar evitar esta conclusión afirmando que para vivir, para investigar no necesitamos el imperativo sé instrumentalmente racional, sino sólo el condicional $P$ : si has de ser racional, optimiza los medios para el logro de tus metas. Pero entonces, resurge el problema, pues cómo justificar sin circularidad el hipotético imperativo $P$.

V. Encontramos análogos compromisos dogmáticos cuando intentamos justificar los métodos de la ciencia. Es de suponerse que la ciencia tiene algún(os) método(s) pues es inverosímil creer que los científicos han logrado los éxitos hasta ahora obtenidos como mero resultado del azar o del capricho. Ahora bien, cualesquiera que sean los métodos de

${ }^{7}$ Cfr., Robert Nozick, The Nature of Rationality, 1993, New Jersey, Princeton University Press. 
¿DOGMATISMO INEVITABLE?

la ciencia es de suponerse que incluirán alguna combinación de deducción e inducción.

La justificación, que no la mera explicación, de la deducción lleva a una regresión al infinito, que sólo puede ser bloqueada postulando como axiomas algunas reglas de inferencia. Por ejemplo, las incesantes peticiones de justificación del modus ponens por parte de la tortuga de Lewis Carroll no pueden ser satisfechas, como él lo hizo notar, sin invocar precisamente lo que se nos pide que justifiquemos, el modus ponens:

Desde luego, podemos probar un metateorema con el propósito de que el modus ponens esté preservando la verdad en el lenguaje-objeto. Sin embargo, la meta-prueba requiere inferencia en el metalenguaje, y esto, a su vez requiere que el metalenguaje tenga el modus ponens o alguna otra regla de inferencia que despierta, por lo menos, iguales sospechas. Para probar que un tipo de regla está preservando la verdad, es necesario tener y usar reglas de deducción en la misma prueba. Por lo tanto, no podemos probar sin circularidad o regresión viciosa que el modus ponens esté preservando la verdad, es decir, no podemos justificar la deducción.

(...) No podemos probar, sin circularidad, que no se encontrará ningún contra-ejemplo del modus ponens. ${ }^{8}$

En cuanto a la inducción Hume célebremente argumentó que nuestra propensión sicológica a hacer inferencias inductivas no justifica estas inferencias. Y que estas inferencias inductivas no pueden ser justificadas deductivamente sin un principio de inducción. Principio que, o tiene que ser aceptado sin sustento o ha de ser justificado por un principio de inducción de orden mayor, y entonces amenaza una regresión al infinito.

${ }^{8}$ W. C. Salmon, "Simposio sobre la evidencia inductiva", (1965), en R. Swinburne (ed.), La Justificación del Razonamiento Inductivo, 1974, Madrid, Alianza, p. 67-9. 


\section{ARMANDO CÍNTORA}

Es decir, no podemos justificar la inducción empíricamente porque para esto necesitamos presuponer la inducción, y no podemos justificarla deductivamente porque no es deducción, excepto si introducimos como premisa un principio de inducción, pero entonces resurge la dificultad al intentar justificar este principio.

$Y$ sin embargo constantemente hacemos inducciones, o creemos que las hacemos, pero dado que no podemos justificar esta propensión sicológica nuestra, hemos de concluir que la misma es irracional o al menos a-racional.

Concluimos entonces que hemos de aceptar tanto la inducción como la deducción dogmáticamente, es decir, sin una justificación no circular. ${ }^{9}$

Se llega a una conclusión análoga cuando buscamos justificar las metas cognitivas de la ciencia. Reichenbach ${ }^{10}$ opinaba que estas metas eran meramente el resultado de 'decisiones volicionales', mientras que Popper las consideraba sólo el resultado de convenciones o propuestas. De ser así las metas de la ciencia serían sólo el resultado de preferencias subjetivas, estarían dictadas por meros prejuicios.

${ }^{9}$ Reichenbach y Salmon, entre otros, no están de acuerdo con esta afirmación y creen que existe un argumento pragmático en favor de la inducción. Este argumento dice: 'si alguna inferencia ampliativa puede ser exitosa, entonces las inferencias inductivas serán exitosas'. El problema es que las inferencias inductivas son sólo un elemento de toda una constelación de plausibles reglas de inferencia, y si hemos de preferir la inducción, hay que aceptar lo que Salmon denomina un 'principio de invariancia lingüística'. Principio que requiere de justificación con lo que resurge el problema escéptico. Además aún si este principio fuese justificado, no es claro que pudiese obviar las paradojas de Goodman.

En cuanto a la deducción, $M$. Dummet ha argumentado que puede ser justificada, sin embargo, 1lega a esta conclusión porque sustituye justificación por explicación. Realmente lo que Dummet hace es explicar cómo funciona la deducción, que no es lo mismo que justificarla. Cfr., H. Reichenbach, The Theory of Probability, (1949), 1971, $2^{\text {nd }}$, USA, University of California Press.

${ }^{10} \mathrm{H}$. Reichenbach, Experience and Prediction, 1938, The University of Chicago Press, p. 10. 
¿DOGMATISMO INEVITABLE?

Se ha intentado justificar, contra Reichenbach y Popper, las metas cognitivas de la ciencia como medios para el logro de fines ulteriores, tales como la sobrevivencia de la especie. Pero aún si esta justificación instrumental de las metas de la ciencia fuese adecuada, tendríamos que nuestra sobrevivencia sería el desideratum injustificable, el fin dogmáticamente valioso.

Nos vemos obligados entonces a concluir que como agentes racionales tenemos que presuponer sin justificación - es decir, dogmáticamente - algunos supuestos: la actitud racional (tanto como búsqueda de justificación que como búsqueda de eficacia en la consecución de nuestros fines), la inducción, la deducción, y algunos fines o valores básicos. Estos cimientos presupuestos marcan las fronteras lógicas de la razón y crean la posibilidad de un relativismo de fundamentos. Este relativismo es, sin embargo, quizás sólo una posibilidad lógica, pues dado nuestro común origen y condición estamos probablemente constreñidos a pensar de cierta forma. De modo que el relativismo de fundamentos aunque lógicamente posible, no es una seria posibilidad sicológica.

VI. Se ha procurado eludir estas conclusiones argumentando que son el resultado de un enfoque errado, de la búsqueda de justificaciones fundacionales, de hacer preguntas demasiado ambiciosas o globales.

Que si fuésemos sensatos nos conformaríamos con preguntas particulares o locales. En otras palabras, se nos dice:

no es razonable preguntar lo que no puede contestarse racionalmente. Tus dudas carecen de justificación, tus dudas no son razonables, no son naturales, pues nuestra ciencia tiene una historia de éxitos o al menos parece tenerla. De éxitos medidos en términos de predictibilidad, de control, de explicación. Y mientras siga teniendo éxito por qué dudar de sus presupuestos. ¡Haz preguntas fructíferas! 


\section{ARMANDO CÍNTORA}

El particularista quiere reformar la filosofía de modo que como la ciencia, avance sin cuestionar estos fundamentos metodológicos. Es decir, quiere que la filosofia proceda dando por supuesto un background knowledge, que proceda con supuestos incuestionados mientras no haya buenas razones para dudar de ellos.

El particularista quiere seguir una estrategia como la del marino de Neurath, quien impedido de tocar tierra y siempre en alta mar, hace pequeñas reparaciones a su navío, según las vaya requiriendo. Y como su navío ha sido confiable no duda de su confiabilidad, mientras no tenga buenas razones para hacerlo, ni intenta hacerle reparaciones preventivas, porque, de hecho, no puede hacerlas. Su lema es: si funciona, no lo repares.

A esta estrategia el escéptico reaccionará diciendo que sus dudas no requieren justificación, que son naturales, que son cuestionamientos intuitivos. Para el escéptico, el localista intenta evadir un problema filosófico y trata de ocultar que requiere de dogmas metodológicos, en otras palabras, para el escéptico el particularista adolece de deshonestidad intelectual, inquiriendo: ¿cómo es que el localista justifica su recomendación por las preguntas locales? ¿cómo es que justifica su supuesto de que las preguntas locales son las únicas razonables, las únicas sensatas?

El particularista podría a su vez intentar justificar su recomendación por las preguntas locales, invocando la concepción medios/fines de la racionalidad, pues según esta concepción no es racional proponerse metas inalcanzables, ya que no pueden guiar la acción, dado que no existe método o medio eficaz para alcanzarlas. Y el particularista agregaría que buscar respuesta a preguntas fundacionales es proponerse una meta inalcanzable, utópica, y por ende no razonable.

Pero, como he argumentado, la concepción medios/fines de la racionalidad no puede ser justificada sin circularidad. De modo que esta descalificación particularista del cuestionamiento escéptico está cimentada en un presupuesto injustificable, y que por lo tanto el escéptico no aceptará. 
¿DOGMATISMO INEVITABLE?

Terminamos entonces con un conflicto de intuiciones, sobre qué ausencia de justificación es más grave: ¿la falta de justificación de las dudas y preguntas del escéptico o la ausencia de justificación de nuestros presupuestos metodológicos?

VII. Entre los muchos filósofos contemporáneos que siguen una estrategia localista, destaca L. Laudan ${ }^{11}$ quien ha propuesto una metametodología de la ciencia que intenta justificar empíricamente los métodos y fines cognitivos de la ciencia y de este modo evitar el relativismo. Laudan, empero, presupone sin justificación, como parte del background knowledge, la deducción, la inducción (lo que él llama $\mathrm{R}_{1}$ ), la racionalidad instrumental, y algunos 'cánones pragmáticos de éxito', tales como la búsqueda de predictibilidad y control.

$\mathrm{Y}$ debido a estos presupuestos injustificados, Laudan no puede eludir, malgré tout, el relativismo fundacional consecuencia de sus presuposiciones injustificables.

Concretamente, para Laudan las reglas metodológicas de la ciencia son 'hipotéticos imperativos' de la forma: si has de ser racional, y si quieres $A$, entonces sigue la regla $M$, donde estos imperativos son respaldados como eficaces por algunas teorías empíricas, teorías sustentadas a su vez en la evidencia empírica, vía algunas otras reglas metodológicas. Y estas últimas reglas metodológicas serán justificadas en su turno como óptimas por otras teorías empíricas, y así ad infinitum. Para detener esta regresión, Laudan invoca una regla inductiva, $\mathrm{R}_{1}$ :

Si las acciones de un cierto tipo, $\mathrm{m}$, sistemáticamente han promovido en el pasado algunos fines cognitivos, e, y si las acciones rivales, n, no lo han logrado, entonces suponga que las acciones futuras que sigan la regla 'si tu meta es e, debes hacer

${ }^{11}$ Cfr., L. Laudan, Progress or Rationality? The Prospects for Normative Naturalism, 1987, American Philosophical Quaterly, 24, n 1, p. 19-31. 


\section{ARMANDO CÍNTORA}

m' son más probables como promotoras de esos fines que las acciones basadas en la regla 'si tu meta es e, debes hacer n'. ${ }^{12}$

Laudan intenta defender $R_{1}$ con las siguientes dos afirmaciones,

$R_{1}$ parece ser una regla sólida para aprender de la experiencia. De hecho si $\left(R_{1}\right)$ no es sólida, ninguna regla lo es. ${ }^{13}$

Ahora, no parece posible justificar sin circularidad la primera afirmación, pues son nuestras convicciones inductivas las que nos dirán si $\mathrm{R}_{1}$ es 'sólida'. En cuanto a la segunda afirmación, relativa al condicional, requiere de justificación porque no es obvia, como lo ejemplifican popperianos como David Miller, que consideran $-\mathrm{o}$ al menos eso dicen- que la inducción es prescindible y un mero mito metodológico. ${ }^{14}$

Laudan requiere de la inducción, de $\left(\mathrm{R}_{1}\right)$, pero no la justifica sin circularidad. La inducción es meramente aceptada, dada por un hecho, y esta situación crea otra vez la posibilidad lógica de un relativismo fundacional. ${ }^{15}$

VIII. En conclusión, algunos dogmas o axiomas, es decir supuestos injustificables, son inevitables porque todo argumento requiere de premisas. Este hecho tan sencillo a veces se olvida o bien se oculta o

${ }^{12}$ Laudan, op. cit., p. 25.

${ }^{13}$ Ibid., p. 26.

${ }^{14}$ Además la defensa pragmática de la inducción a la que hace alusión el condicional si $\left(R_{l}\right)$ no es sólida, ninguna regla lo es, tiene que lidiar con las dificultades mencionadas en la nota anterior $n^{\circ} 7$.

${ }^{15} \mathrm{~J}$. Worrall ha argumentado que la propuesta de Laudan tampoco puede eludir otra forma de relativismo: el relativismo histórico. Esto porque para Laudan tanto los métodos, las teorías, como las metas de la ciencia pueden cambiar, y de ser así no hay entonces estándares absolutos de progreso científico. De hecho, el progreso científico es para Laudan sólo relativo a 'nuestras luces' en un momento histórico dado (Cfr. Laudan, op. cit., p. 28). 
¿DOGMATISMO INEVITABLE?

disfraza por medio de argumentos circulares; pero, la circularidad es lógicamente equivalente al dogmatismo. La circularidad puede ser difícil de descubrir cuando los círculos son suficientemente amplios e inclusivos; mas, aparente o no, la circularidad, o su equivalente el dogmatismo, es finalmente inevitable.

Hay, sin embargo, una diferencia de matiz, de énfasis, de honestidad intelectual entre la circularidad y el dogmatismo. Mientras que el dogmático acepta abiertamente que requiere de axiomas, quien argumenta en círculos intenta ocultar este requerimiento.

La circularidad es un eufemismo, es el apelativo 'políticamente correcto' del dogmatismo. 